\title{
Les vétérinaires luttent contre d'autres problématiques
}

\section{Patrizia Andina}

Dr méd. vét., médecine des ruminants, Société des Vétérinaires Suisses, responsable médicaments vétérinaires et actes vétérinaires

\author{
La consommation d'antibiotiques diminue en médecine vétérinaire. Pourquoi il \\ n'est pas possible de renoncer intégralement aux antibiotiques et où se situent les \\ défis d'une réduction supplémentaire.
}

À titre de médecins pour animaux, les vétérinaires sont tenus de soigner ceux-ci. Dans le domaine des animaux de compagnie, ils s'occupent de proches accompagnants de l'être humain. Dans celui des animaux de rente, ils sont responsables de la sécurité des denrées alimentaires dans le segment des produits animaux et, ce faisant, d'un secteur de la santé publique. Dans un domaine comme dans l'autre, l'homme et l'animal sont très proches. Cela plaide en faveur d'une approche commune du problème des résistances aux antibiotiques. Une problématique est toutefois spécifique à la médecine des animaux de rente: on est rarement face à un seul animal affecté, mais à des groupes entiers. L'exemple suivant est là pour l'illustrer.

\section{Bob, le veau «en trop»}

Bob est né il y a trois semaines. C'est le veau mâle d'une vache laitière et, comme la majeure partie de ses collègues, il n'a pas les qualités d'un taureau d'élevage et sera donc engraissé. L'investissement financier pour l'affouragement, les soins et la garde correspondant déjà au prix de vente pour ce veau de vache laitière de constitution plutôt fine, le propriétaire peut s'attendre à juste couvrir les frais, sans plus. Mais cela pour autant que l'animal ne tombe pas malade auparavant.

Bob est né à 2 heures du matin. L'agriculteur a surveillé le vêlage. Pour des questions d'hygiène, il a immédiatement retiré le veau de sa mère et l'a placé sur une litière propre. Ensuite, il est retourné au lit. Après la traite du matin à 6 heures, Bob a reçu sa première portion de colostrum.

\section{Un autre placenta}

À titre de ruminant, Bob n'a pas reçu d'immunoglobulines $\mathrm{G}$ de sa mère par voie transplacentaire. Il doit donc couvrir l'intégralité de ses besoins en anticorps via le colostrum. Pour Bob, la première administration de colostrum est arrivée trop tard. Il est donc hypogammaglobulinémique.

\section{Transport et sevrage d'animaux non immunocompétents}

Aujourd'hui, à l'âge de 21 jours, le veau doit déjà quitter l'exploitation de sa naissance. Un commerçant vient le chercher pour faire la tournée d'autres exploitations et rassembler des veaux dans un camion, pour les livrer chez l'engraisseur. Bob sera mis en étable avec 39 autres jeunes animaux dans un seul et même local. Trenteneuf souches de virus inconnues rencontrent 39 autres petits veaux. Certains d'entre eux souffrent déjà d'infections cachées, comme des abcès ombilicaux internes ou des otites. L'engraisseur les vaccine certes contre les souches de virus usuelles, mais après cinq jours, les premiers veaux sont si atteints que le vétérinaire de l'exploitation décide de traiter tous les veaux durant cinq jours contre la pneumonie (métaphylaxie). Le médicament est administré via les automates de distribution du lait. Le vétérinaire, qui a conclu une convention avec l'engraisseur, a prescrit le médicament avec une ordonnance complète. Il a dû à cet effet suivre une formation postgrade reconnue par la Confédération et clôturée par un examen, et doit rafraîchir ses connaissances tous les cinq ans. Le vétérinaire accompagne étroitement le traitement chez l'engraisseur et documente la consommation des antibiotiques. Certains animaux sont souvent si fortement atteints qu'ils boivent trop peu et doivent être séparés pour être traités par voie systémique.

\section{Diagnostic difficile}

L'exemple de Bob est typique de ce que l'on rencontre dans l'engraissement. Les problèmes rencontrés dans 


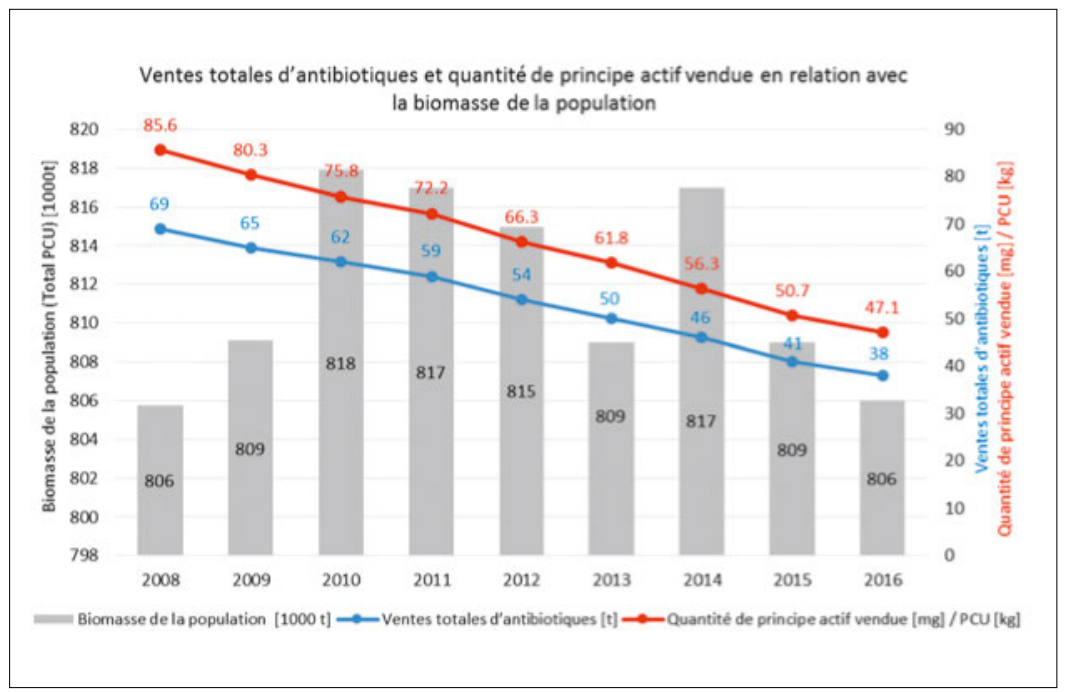

Ventes totales d'antibiotiques en médecine vétérinaire 2006-2016: seul le poids total des antibiotiques vendus par les entreprises pharmaceutiques aux vétérinaires en Suisse est actuellement enregistré.

les autres secteurs des animaux de rente ont un certain nombre de similitudes.

Les tentatives de mettre en étable des veaux sans traitement antibiotique sont souvent voués à l'échec. Un vétérinaire en pratique rurale n'a par ailleurs pas vraiment de possibilités d'assurer un diagnostic clinique: il n'existe pas de test permettant de distinguer rapidement, sur un animal de rente, une pneumonie virale d'une pneumonie bactérienne (par analogie à la protéine $C$ réactive ou la procalcitonine). Il n'y a pas non plus de caisse-maladie qui participe financièrement à ces tests laborieux. Par ailleurs, les bovins réagissent rapidement aux pneumonies bactériennes par la formation d'adhérences des plèvres et d'abcès. Il est donc essentiel que le vétérinaire réagisse rapidement, souvent en prescrivant des antibiotiques, si l'on veut préserver le bien-être de l'animal.

\section{Engagement des vétérinaires en pratique rurale}

Les vétérinaires en pratique rurale de Suisse fournissent de gros efforts pour réduire le besoin d'antibiotiques dans les détentions d'animaux. Il n'existe pas de panacée: différentes mesures ont donc déjà été initiées ou mises en œuvre. Le conseil des détenteurs d'animaux en est un des piliers, car il importe de mettre en œuvre des mesures préventives afin d'optimiser la garde. Dans le cas de Bob, cela signifierait optimiser l'administration de colostrum de même que les program- mes de vaccination. Il convient en outre de veiller à ce que le diagnostic soit financièrement supportable et d'en démontrer l'utilité durable pour l'éleveur. Les services sanitaires pour animaux fournissent pour leur part de précieux services depuis plusieurs années en faveur de la santé animale, en proposant leur aide aux détenteurs d'animaux et aux vétérinaires à titre d'associations de spécialistes dans la prévention et la gestion. Un service sanitaire pour les veaux est actuellement en voie d'établissement.

En collaboration avec la Confédération et dans le cadre de la Stratégie Antibiorésistance (StAR), des mesures supplémentaires sont discutées avec les acteurs de la branche. Ainsi, les vétérinaires ont développé des directives de traitement pour le secteur des animaux de rente. Dès 2019, ils devraient en outre consigner toute utilisation d'antibiotiques dans une banque de données fédérale (loi sur les produits thérapeutiques et ordonnance SIABV). Ces données devront permettre de déterminer dans quel contexte ont lieu le plus souvent les traitements aux antibiotiques. Cela permettra à nouveau de conseiller et d'informer de manière plus ciblée.

Le désamorçage du problème décrit pourrait cependant aussi pouvoir être obtenu grâce à un engraissement plus fréquent des veaux dans leur exploitation d'origine. Externaliser le plus tôt possible le suivi des jeunes veaux, lourd en termes de temps investi et de finances, est cependant usuel de nos jours et découle de la pression sur les coûts constatée dans l'agriculture. Un changement de système requiert au préalable un changement d'attitude dans l'agriculture, mais aussi au niveau de la commercialisation et dans la société. Il y a fort à parier que les prix des produits augmenteraient. Tuer immédiatement les veaux "en trop" comme Bob à la naissance ou déplacer l'engraissement à l'étranger ne sont pas non plus des solutions envisageables. Nous devons résoudre ce problème en Suisse. On ne peut aujourd'hui envisager un élevage qui se passe de l'administration d'antibiotiques. Les vétérinaires travaillent toutefois de manière intensive à n'utiliser les antibiotiques que de manière ciblée, uniquement lorsqu'ils s'avèrent absolument nécessaires et à réduire le besoin d'antibiotiques. La statistique des antibiotiques dans le secteur animal montre que nous sommes sur la bonne voie.

\section{Crédit graphique} OSAV 